\title{
EDITORIAL
}

\section{When asthma diagnosis becomes a challenge}

\author{
M. Contoli and A. Papi
}

13 sthma is a worldwide disease affecting an estimated 300 million individuals $[1,2]$. Some authors refer to the increased prevalence of asthma reported during the past decades, in many parts of the world, as a wave of "asthma epidemic" [3]. Given the recent increase in asthma-related healthcare costs [4], it has become important, in a time of economical restriction, to critically review the dimensions of this phenomenon and to investigate the underlying causes. First of all, is there a real epidemic threat? Indeed, besides several proposed explanations for increasing asthma prevalence (e.g. exposure to tobacco smoke, air pollution and specific allergens, change in diet intake, obesity, exposure to infections and microbial substance in the environment) [3], there has also been an improved awareness of the disease over the past few years. Substantial effort has been made in the past decade for the development and the dissemination of international asthma guidelines. Such widespread publicity has certainly contributed to improve asthma management worldwide and to identify and treat new asthmatic patients. However, it might also have caused overdiagnosis of asthma and, more specifically, it may have contributed to the increased proportion of incorrectly diagnosed asthma cases. Inevitably, any misdiagnosed cases lead to over treatment or inappropriate treatments [5], and increased risk of side-effects in the absence of any pharmacological benefit.

Is it only a hypothetical situation? Unfortunately it does not appear to be a mere theory. International guidelines advise that asthma diagnosis be based on both the presence of symptoms and objective measurements of variable airflow obstruction $[1,2]$. Spirometry, when it shows reversible airflow obstruction, and/or bronchial challenge, and when it identifies bronchial hyperresponsiveness, is a highly valuable diagnostic tool in patients with a clinical history suggestive of asthma. However, in daily practice, there are important barriers to performing lung function tests which can occur more frequently in a primary care setting but also in secondary care settings [6-8]. Under these conditions one can be tempted to initiate asthma medication in patients presenting with asthma symptoms, without putting any effort into further diagnostic investigations. Recent studies indicate that many of the diagnoses of asthma in primary care rely solely on clinical evaluation and/or response to treatment [9]. Thus, the risk of misdiagnosed asthma is not a hypothesis and it could

Research Centre on Asthma and COPD, Dept of Clinical and Experimental Medicine, Section of Respiratory Disease, University of Ferrara, Ferrara, Italy.

CORRESPONDENCE: M. Contoli, Research Centre on Asthma and COPD, Dept of Clinical and Experimental Medicine, Section of Respiratory Disease, University of Ferrara, Via Savonarola 9, 44121 Ferrara, Italy. E-mail: ctm@unife.it become a real issue. In a Swedish study, where patients on a primary care asthma register underwent a comprehensive diagnosis re-evaluation, asthma could not be confirmed in more than one third of patients [10]. Similarly, in a sample population of physician-labelled asthmatics, $41 \%$ showed no evidence of reversible airflow obstruction and had a negative methacholine challenge [11]. More recently, AARON et al. [12] reported that asthma was ultimately excluded in $30 \%$ of physician-diagnosed asthmatic patients based on the absence of acute worsening of asthma symptoms, reversible airflow obstruction or bronchial hyperresponsiveness after withdrawal of asthma medication. Taken together, these findings document that asthma overdiagnosis/misdiagnosis is not a rare event in daily practice. Obvious consequences are, on the one hand, inappropriate and most probably unsuccessful treatment and, on the other hand, increased costs and increased risk of adverse events. This issue becomes even more crucial in the light of the recently renewed US Food and Drug Administration warning on the appropriateness of the use of long-acting $\beta_{2}$-agonists in association with inhaled corticosteroids [13].

In daily clinical practice, how often do we confirm existing asthma treatments without inquiring too much on the appropriateness of the original diagnosis? How often do we doubt the diagnosis in patients labelled as asthmatics and treated accordingly but free of symptoms for a long time? How often do we visit patients that, due to difficulty in accessing healthcare facilities, are treated based on a clinical suspicion but awaiting lung function testing? In all these circumstances, the (re)confirmation/assessment of asthma diagnosis is a true medical need. Unfortunately, international guidelines do not provide validated strategies to confirm or exclude asthma in patients already labelled and treated as asthmatics.

In the current issue of the European Respiratory Journal, LUKS et al. [14] propose a practical approach to this topic. In a previous study, AARON et al. [12] found that about one-third of individuals with physician-diagnosed asthma did not have asthma when objectively assessed. In this study they applied a stepwise diagnostic approach to the same cohort of patients to confirm or exclude a previous physician diagnosis of asthma. First, the authors confirm their previous finding that in $\sim 30 \%$ of patients the previous diagnosis of asthma could be excluded. This finding quantifies the magnitude of the risk of misdiagnosed asthma, clearly indicating the relevance of this issue. Secondly, the authors report that reversibility testing and methacholine challenge are sufficient to confirm asthma for the vast majority of patients $(\sim 95 \%)$ irrespective of any ongoing asthma treatment. Thus, withholding or tapering asthma medication is not generally required to confirm the diagnosis of asthma. Thirdly, in only a minority of patients was tapering 
or withdrawal of regular treatment necessary to document bronchial hyperresponsiveness. Of note, up to one-third of patients in whom asthma was excluded did resume taking an asthma medication at some point during the 6-month followup period.

The effort made by the authors in their attempt to identify an easy and time saving protocol to confirm asthma diagnosis has to be appreciated. However, some doubts remain. In the study by LUKS et al. [14] the presence of bronchial hyperresponsiveness has been used to definitely exclude or confirm asthma diagnosis. Although the sensitivity of methacholine challenge is well recognised, its specificity is of some concern [15, 16]. Examples include the following: 1) several studies have reported that airway hyperresponsiveness is enhanced in patients with allergic rhinitis and no asthma [17-19]; 2) there is evidence that cigarette smoke can acutely increase bronchial hyperresponsiveness [20-22] by inducing the release of proinflammatory mediators and/or by interfering with the metabolism of bronchoconstriction mediators [23]; 3) clinical conditions characterised by airflow limitation can be associated with bronchial hyperresponsiveness mainly related to the reduced airways calibre (e.g. chronic obstructive pulmonary disease) $[15,24]$; 4) viral infections of the airways transiently increase airway hyperresponsiveness even in healthy subjects [25]. Thus, other possible causes of bronchial hyperresponsiveness, sometimes presenting with clinical features not dissimilar to asthma should be carefully excluded to avoid false-positive results $[1,2]$. However, the presence of a negative bronchial challenge does not rule out asthma diagnosis. Indeed, bronchial hyperresponsiveness may not always be present in asthmatic patients. For example, a negative methacholine challenge may occur in: seasonal asthmatic patients when tested out of season [26]; workers with occupational asthma due to a single antigen or chemical sensitiser, which may respond only when challenged with the specific agent [27]; and patients taking intensive anti-inflammatory medication [15]. In the study by LUKS et al. [14], $\sim 30 \%$ of patients with a negative methacholine challenge, even after withdrawing all medication, experienced asthma symptoms requiring medical intervention in the following 6 months. Can we totally exclude asthma in these patients? If not, as appears to be the case, the approach proposed in the present study needs to be improved in order to better identify truly negative results. One possible falsenegative result out of three negative results might not be of great clinical help, and it questions the sensitivity of the decision process based on the algorithm proposed by the authors. However, since no absolute and unanimously accepted protocol is available to evaluate the accuracy of pre-existing asthma diagnosis, the study presented by LUKS et al. [14] should be merited with having raised such a relevant issue and for proposing a valuable but perfectible strategy.

\section{STATEMENT OF INTEREST}

None declared.

\section{REFERENCES}

1 Bateman ED, Hurd SS, Barnes PJ, et al. Global strategy for asthma management and prevention: GINA executive summary. Eur Respir J 2008; 31: 143-178.
2 Global Initiative for Asthma. Global Strategy for Asthma Management and Prevention. 2008 Update. Publication No. 023659: 1-116. NHLBI/WHO workshop report. Bethesda, National Institutes of Health, National Heart, Lung and Blood Institute, 2008. www.ginasthma.com/Guidelineitem.asp??11 $=2 \& 12=1 \&$ intId $=60$

3 Eder W, Ege MJ, von Mutius E. The asthma epidemic. N Engl J Med 2006; 355: 2226-2235.

4 Bahadori K, Doyle-Waters MM, Marra C, et al. Economic burden of asthma: a systematic review. BMC Pulm Med 2009; 9: 24.

5 Lucas AE, Smeenk FW, Smeele IJ, et al. Overtreatment with inhaled corticosteroids and diagnostic problems in primary care patients, an exploratory study. Fam Pract 2008; 25: 86-91.

6 Caramori G, Bettoncelli G, Tosatto R, et al. Underuse of spirometry by general practitioners for the diagnosis of COPD in Italy. Monaldi Arch Chest Dis 2005; 63: 6-12.

7 Miravitlles M, de la Roza C, Naberan K, et al. Use of spirometry and patterns of prescribing in COPD in primary care. Respir Med 2007; 101: 1753-1760.

8 Riario-Sforza GG, Incorvaia C, Pravettoni C, et al. Guidelines versus clinical practice in the treatment of COPD: a reappraisal. Eur Respir J 2006; 27: 656.

9 Caramori G, Bettoncelli G, Carone M, et al. Degree of control of physician-diagnosed asthma and COPD in Italy. Monaldi Arch Chest Dis 2007; 67: 15-22.

10 Marklund B, Tunsater A, Bengtsson C. How often is the diagnosis bronchial asthma correct? Fam Pract 1999; 16: 112-116.

11 LindenSmith J, Morrison D, Deveau C, et al. Overdiagnosis of asthma in the community. Can Respir J 2004; 11: 111-116.

12 Aaron SD, Vandemheen KL, Boulet LP, et al. Overdiagnosis of asthma in obese and nonobese adults. CMAJ 2008; 179: 1121-1131.

13 Chowdhury BA, Dal Pan G. The FDA and safe use of long-acting beta-agonists in the treatment of asthma. N Engl J Med 2010; 362: 1169-1171.

14 Luks VP, Vandemheen KL, Aaron SD. Confirmation of asthma in an era of overdiagnosis. Eur Respir J 2010; 36: 255-260.

15 Crapo RO, Casaburi R, Coates AL, et al. Guideline for methacoline and exercise challenge testing 1999. The Offical Statement of the American Thoracic Society was adopted by the ATS Board of Directors, July 1999. Am J Respir Crit Care Med 2000; 161: 309-329.

16 Cockcroft DW, Murdock KY, Berscheid BA, et al. Sensitivity and specificity of histamine PC20 determination in a random selection of young college students. J Allergy Clin Immunol 1992; 89: 23-30.

17 Cirillo I, Pistorio A, Tosca M, et al. Impact of allergic rhinitis on asthma: effects on bronchial hyperreactivity. Allergy 2009; 64: 439-444.

18 Ramsdale EH, Morris MM, Roberts RS, et al. Asymptomatic bronchial hyperresponsiveness in rhinitis. J Allergy Clin Immunol 1985; 75: 573-577.

19 Shaaban R, Zureik M, Soussan D, et al. Allergic rhinitis and onset of bronchial hyperresponsiveness: a population-based study. Am J Respir Crit Care Med 2007; 176: 659-666.

20 Menon P, Rando RJ, Stankus RP, et al. Passive cigarette smokechallenge studies: increase in bronchial hyperreactivity. J Allergy Clin Immunol 1992; 89: 560-566.

21 Jensen EJ, Dahl R, Steffensen F. Bronchial reactivity to cigarette smoke in smokers: repeatability, relationship to methacholine reactivity, smoking and atopy. Eur Respir J 1998; 11: 670-676.

22 Cerveri I, Bruschi C, Zoia MC, et al. Smoking habit and bronchial reactivity in normal subjects. A population-based study. Am Rev Respir Dis 1989; 140: 191-196.

23 Dusser DJ, Djokic TD, Borson DB, et al. Cigarette smoke induces bronchoconstrictor hyperresponsiveness to substance $\mathrm{P}$ and inactivates airway neutral endopeptidase in the guinea pig. Possible role of free radicals. J Clin Invest 1989; 84: 900-906.

24 Ramsdale EH, Morris MM, Roberts RS, et al. Bronchial responsiveness to methacholine in chronic bronchitis: relationship to 
airflow obstruction and cold air responsiveness. Thorax 1984; 39: 912-918.

25 Message SD, Laza-Stanca V, Mallia P, et al. Rhinovirus-induced lower respiratory illness is increased in asthma and related to virus load and Th1/2 cytokine and IL-10 production. Proc Natl Acad Sci USA 2008; 105: 13562-13567.
26 Cockcroft DW. Allergen-induced increase in nonallergic airway responsiveness: a citation classic revisited. Can Respir J 2000; 7: 182-187.

27 Tarlo SM, Balmes J, Balkissoon R, et al. Diagnosis and management of work-related asthma: American College of Chest Physicians Consensus Statement. Chest 2008; 134: Suppl. 3, 1S-41S. 